\title{
Investigation of Microbial Respirometry for Monitoring Natural Sulfide Abatement in Geothermal Cooling Tower Basins
}

Peter A. Pryfogle

September 2005

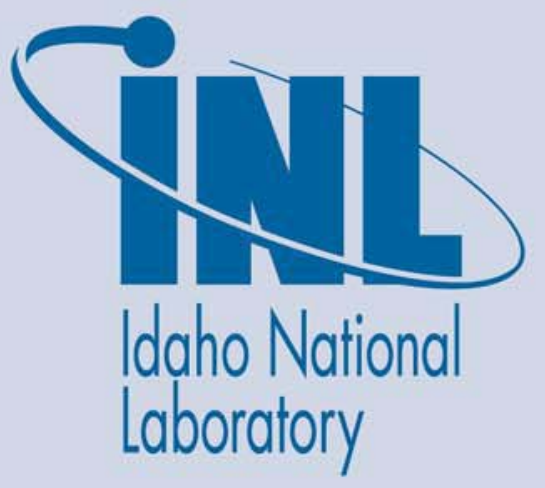

The INL is a U.S. Department of Energy National Laboratory operated by Battelle Energy Alliance 
INL/EXT-09-16473

\title{
Investigation of Microbial Respirometry for Monitoring Natural Sulfide Abatement in Geothermal Cooling Tower Basins
}

\author{
Peter A. Pryfogle
}

September 2005

Idaho National Laboratory
Idaho Falls, Idaho 83415

http://www.inl.gov

Prepared for the

U.S. Department of Energy

Assistant Secretary for Energy Efficiency and Renewable Energy Under DOE Idaho Operations Office

Contract DE-AC07-05ID14517 


\begin{abstract}
Geothermal plant operators are interested in investigating the ability of micro-organisms found in the cooling tower basin to metabolize and cycle sulfide to less toxic sulfur compounds. If the growth or activity of the organisms participating in sulfur-oxidation could be selectively enhanced, then hydrogen sulfide could be naturally abated in the cooling basin, substantially reducing the costs associated with the chemicals used for abatement.

The use of respirometry has been proposed as a technique for monitoring the response of the microbial populations found in geothermal cooling towers to various conditions, including the addition of nutrients such as nitrogen and phosphorus. Respirometry is a manometric measurement of dissolved gases that are in equilibrium in a con-fined sample volume. Since microbes expire varying amounts of carbon dioxide or oxygen as they metabolize nutrients, this technique can be used to evaluate their activities in process streams. This report describes a series of experiments designed to determine the suitability of respirometry for tracking microbial activity for evaluating and enhancing natural abatement processes in geothermal cooling basins.
\end{abstract}




\section{ACKNOWLEDGMENTS}

This document is an interim report that was prepared to prior to the Department of Energy's decision to terminate funding for research activities. This work was supported by the U. S. Department of Energy, Assistant Secretary for Energy Efficiency and Renewable Energy, under DOE Idaho Operations Contract DE-AC07-05ID14517. 


\section{Table of Contents}

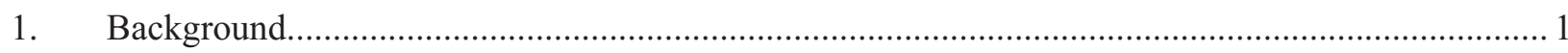

2. Experimental Apparatus and Protocol ..................................................................................... 2

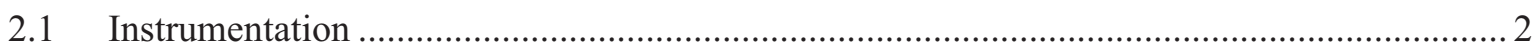

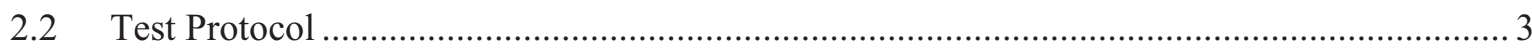

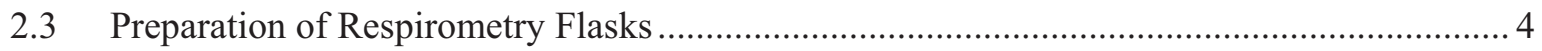

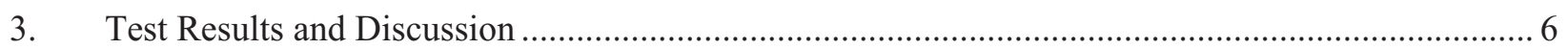

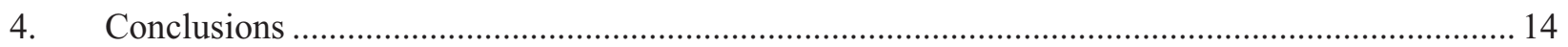




\section{Investigation of Microbial Respirometry for Monitoring Natural Sulfide Abatement in Geothermal Cooling Tower Basins}

\section{BACKGROUND}

For several years the INEEL has been involved in research directed at identifying various types of bacteria at geothermal power plants and investigating their impact on operational parameters. Previous work indicated microbial number densities can be as high as $10^{6}$ cells $/ \mathrm{ml}$ in the condenser cooling water. This community of microorganisms includes heterotrophic bacteria, sulfate reducers, and acid formers. Some may be potentially harmful to plant operations, creating conditions conducive to the degradation, or corrosion, of metal surfaces, and others may aid in the production of biofilms, reducing the efficient transfer of heat on the condenser tube surfaces. More recently the work has included the identification and study of bacteria that may be beneficial to power plant operations. Sulfur oxidizing bacteria, present in the cooling tower flow, may participate in the oxidation of fugitive sulfides thus aiding in sulfide abatement. The promotion of these bacteria could result in a substantial cost savings at the plants by reducing the volume of abatement chemicals, which are currently conservatively applied to meet state and federal environmental regulations for sulfide emissions.

The goal of this effort is to maintain, and if possible enhance, the useful activities of microorganisms while at the same time controlling and reducing the negative impacts of biofilm formation and microbially-influenced corrosion (MIC). A key element of this work is to develop techniques for tracking these activities. The project is being per-formed in collaboration with the Calpine Corporation at the Geysers. Calpine has an interest in evaluating the impact of nutrients from re-injected wastewater on the microbial communities in their geothermal plant cooling systems, and in particular would like to determine if alterations in water chemistry could be used to enhance natural sulfide abatement.

In late 1997, tertiary treated water (TTW) was collected from the south end of Lake County, piped to the Southeast end of The Geysers basin, and injected into the subsurface in an attempt to stop (and reverse) steam production and quality loss in the steam reservoir. This effort represented a huge cost savings for the communities of Lake County and a valuable resource to the geothermal power operations at The Geysers. Initial results were promising and indicated successful recovery of steam quality in the basin.

A similar plan was developed for the Central basin of The Geysers using TTW from Santa Rosa, CA. In addition to using this water for subsurface injection and reservoir enhancement, the use of this water as make up for evaporative loss in the cooling towers at geothermal power plants during the summer months when water loss is high and resources are in demand was also considered. There were concerns on the use of the wastewater as make-up for the cooling towers, since it would carry concentrations of nutrients (i.e., nitrates, phosphates, soluble carbon) that might stimulate bacterial growth in the cooling tower basins and circulation flow. As part of the laboratory collaboration, the application of differential respirometry was selected as an initial step directed at determining the response of the cooling tower microbial population to the addition of the Santa Rosa TTW.

Respirometry is based upon a manometric measurement of dissolved gases that are in equilibrium in a confined sample volume. Since microbes expire varying amounts of carbon dioxide or oxygen as they metabolize nutrients, this technique can be used to evaluate their activities in process streams.

Respirometry is a well-established tool for process control in the biological treatment of wastewater and has also been used to assess the biodegradation of specific chemicals. And, while it is most commonly 
performed on samples in a laboratory environment, it is also possible to implement as an on-line instrument.

This report presents the results of a series of experiments using water from the Sonoma geothermal plant cooling basin operated by Calpine at the Geysers in northern California. The Sonoma facility was selected for study since it plans to use the Santa Rosa TTW as tower make-up during the summer months. The goal of the experiments were to determine if differential respirometry could track changes in microbial activity induced by changing the nutrient concentration under various conditions in this process stream.

\section{EXPERIMENTAL APPARATUS AND PROTOCOL}

\subsection{Instrumentation}

A Gibson Respirometer, shown in Figure 1, was used in the experiments. The instrument consists of a series of tubes and two chambers separated by a manometer U-tube. One of these chambers is the reaction flask and the other serves as reference flask, or thermobarometer, acting as a control for small temperature or pressure changes in the water bath. The two flasks are initially open and in equilibrium with the surrounding environment. During testing, the system is sealed so that one side maintains the head-space volume at the time of closure while the other contains the test solution and materials. If gas is either used up (e.g. oxygen consumed) or produced (carbon dioxide expired) in the reaction flask, a differential change in gas pressure is detected. (In this instrument, the carbon dioxide is scrubbed out of the system by an alkali resulting in a negative gas pressure.) The change in pressure causes fluid to move in the U-tube. Turning one of the knurled knobs, shown at the top left in the picture, causes a metal plunger to change the volume on the reaction vessel side of the tube and when the fluid is moved back to its original starting point, the volume change is indicated on the dial in microliters. The respirometer also contains a circulating water bath to control the temperature of the reaction flasks and shaker feature that can be used to stir the test solutions. Prior to testing, the water bath was filled with nanopure water, the stirring motor and heaters were activated, and the system was allowed to stabilize for approximately one hour. 


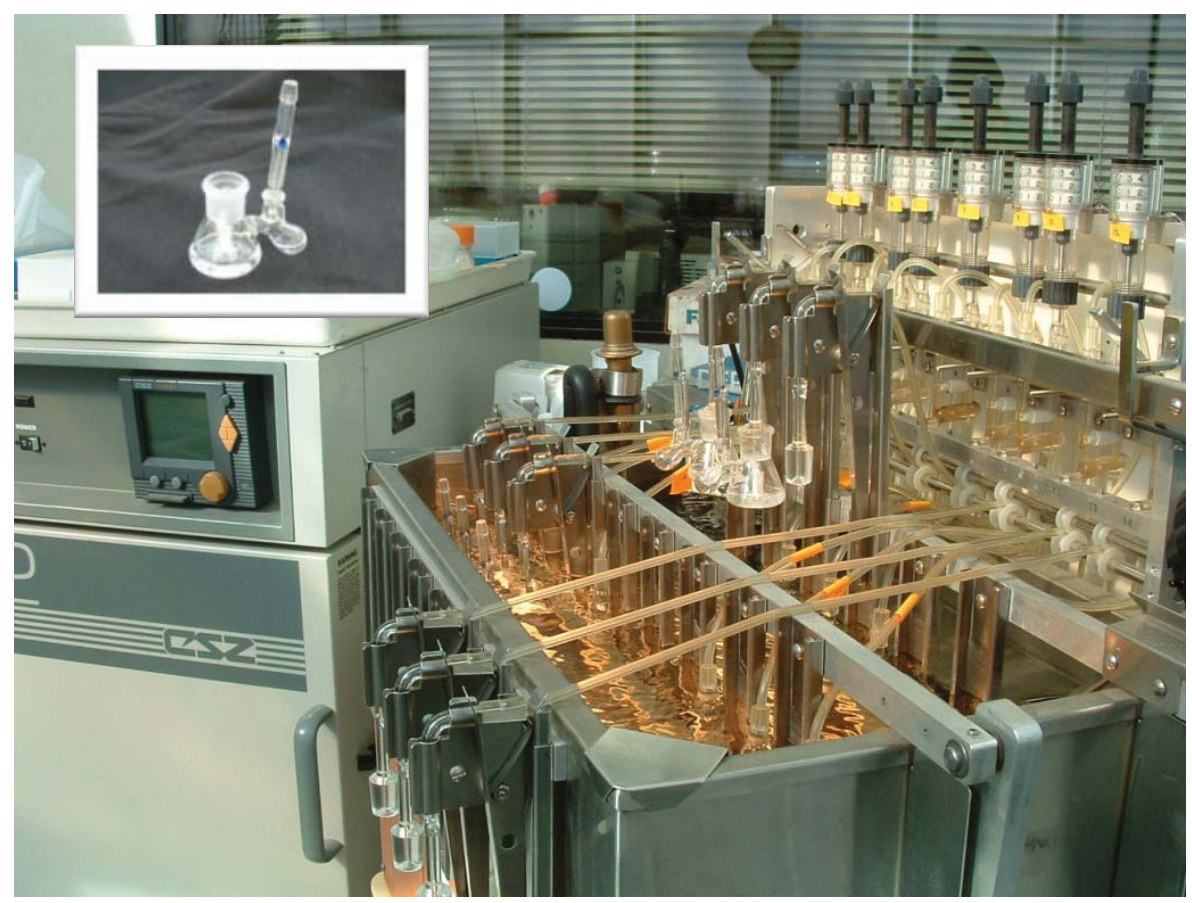

Figure 1. Gibson Differential Respirometer and Close-up of $15 \mathrm{~mL}$ Reaction Flask

\subsection{Test Protocol}

Nine slots were available in the instrument for inserting the $15 \mathrm{ml}$ test flasks. Consequently, the experiments were typically conducted using a control and two different test conditions. Three replicate samples were tested for each parameter. The test groups were distributed at different locations, as shown in Figure 2, in order to further minimize the possibility of differences due to uneven heating.

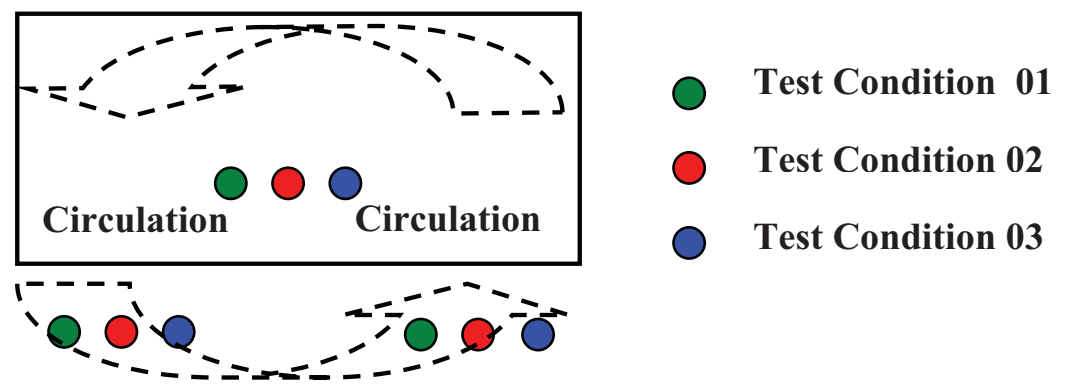

Respirometer

Figure 2. Sample Flask Deployment in the Gibson Differential Respirometer 
A typical sample preparation for a nutrient concentration test is shown in Table 1. The total test volume used in the testing was $5 \mathrm{ml}$. Following the experiments, approximately $0.5 \mathrm{ml}$ of the sample was used for making biological cell counts and $1.0 \mathrm{ml}$ was used for sulfate or other trace chemical analyses.

Table 1. Sample Preparation

\begin{tabular}{|c|c|c|}
\hline Condition 01 (control) & Condition 02 & Condition 03 \\
\hline $4.7 \mathrm{ml}$ Sonoma Water & $4.7 \mathrm{ml}$ Sonoma Water & $4.7 \mathrm{ml}$ Sonoma Water \\
\hline $0.3 \mathrm{ml}$ Sterile Water & $0.2 \mathrm{ml}$ Sterile Water & $0.1 \mathrm{ml}$ Sterile Water \\
\hline & $0.1 \mathrm{ml} 1,000 \mathrm{ppm}$ Nutrient & $0.2 \mathrm{ml} \mathrm{1,000ppm} \mathrm{Nutrient}$ \\
\hline
\end{tabular}

\subsection{Preparation of Respirometry Flasks}

The flasks used in the testing were prepared and installed according to the following procedure.

1) All flasks were washed with soapy water before use.

2) All flasks were acid rinsed in a $2 \% \mathrm{HCl}$ solution before use.

3) All flasks were rinsed with de-ionized water and air-dried.

4) The clean, dry respirometry flasks were then prepared and loaded with the constituents required for the test.

5) The valves on the respirometer were opened to establish an atmospheric equilibrium between the chamber sides of the system.

6) The manometer meters (dials) were adjusted to 200 on each station. This permits adjustments up or down according to gas usage or production. The dials should not be turned beyond their endpoints since there is the possibility of damaging the seals on these components.

7) The ground glass fittings were greased to achieve an air-tight seal.

a) A small container of vaseline was heated to liquefy the contents.

b) A wooden dowel was then dipped into the liquid and drawn across each side of the ground glass leaving a trace of vaseline.

c) A piece of ashless filter paper was folded like an accordion and placed in the center well of the respirometry flask.

d) The ancillary solutions were added to the side-arm flask.

e) The snorkel glass pipe was attached to the side-arm, twisted back-and-forth-evenly distribute the Vaseline, and the springs were attached to hold the pipe in place.

f) A $0.1 \mathrm{~N}$ sodium hydroxide solution $(\sim 0.3 \mathrm{ml})$ was added to the center well and filter paper

g) The bulk test solution (Sonoma cooling basin water) was added to the main flask volume.

h) Once all flasks are filled with bulk water, the ancillary solutions were mixed with the bulk solution by:

1a. Rocking the flask to one side and toward the side-arm flask spilling bulk solution into the side-arm.

1b. Rolling the flask back to the original position and then rocking back, spilling the contents of the side-arm into the main volume.

Note: The flask must be rolled carefully so as not to spill the solutions into the center well containing the potassium hydroxide.

1c. This procedure was repeated two more times for complete mixing of the bulk and ancillary solutions.

i) Upon completing the final mix, the flask was attached to the glass fitting on the respirometer.

8) The flask was twisted back-and-forth to distribute the vaseline. 
9) The springs were then attached to securely hold the respirometer flask in position

10) The flask was lowered into the water bath.

11) Once all flasks were prepared, attached to the respirometer and lowered into the water bath, a 5-minute timer was set to allow thermal equilibration to occur.

12) The meniscus lines are aligned with the level of the manometer fluid.

13) After thermal equilibration was achieved, the manifold valves were closed and the test began

14) Every 10-minutes the style for each test flask was adjusted to float the level of the manometer fluid on the meniscus line, and the value recorded from the adjusted style.

15) At the end of the test, the equilibration valve was opened on each flask.

16) Test flasks were removed and the samples were analyzed.

The following form, shown in Table 2, was used to record the data. Since preliminary testing indicated that activity tended to flatten out after approximately 60-70 minutes, tests were seldom run past an hour.

Table 2. Data Collection Form

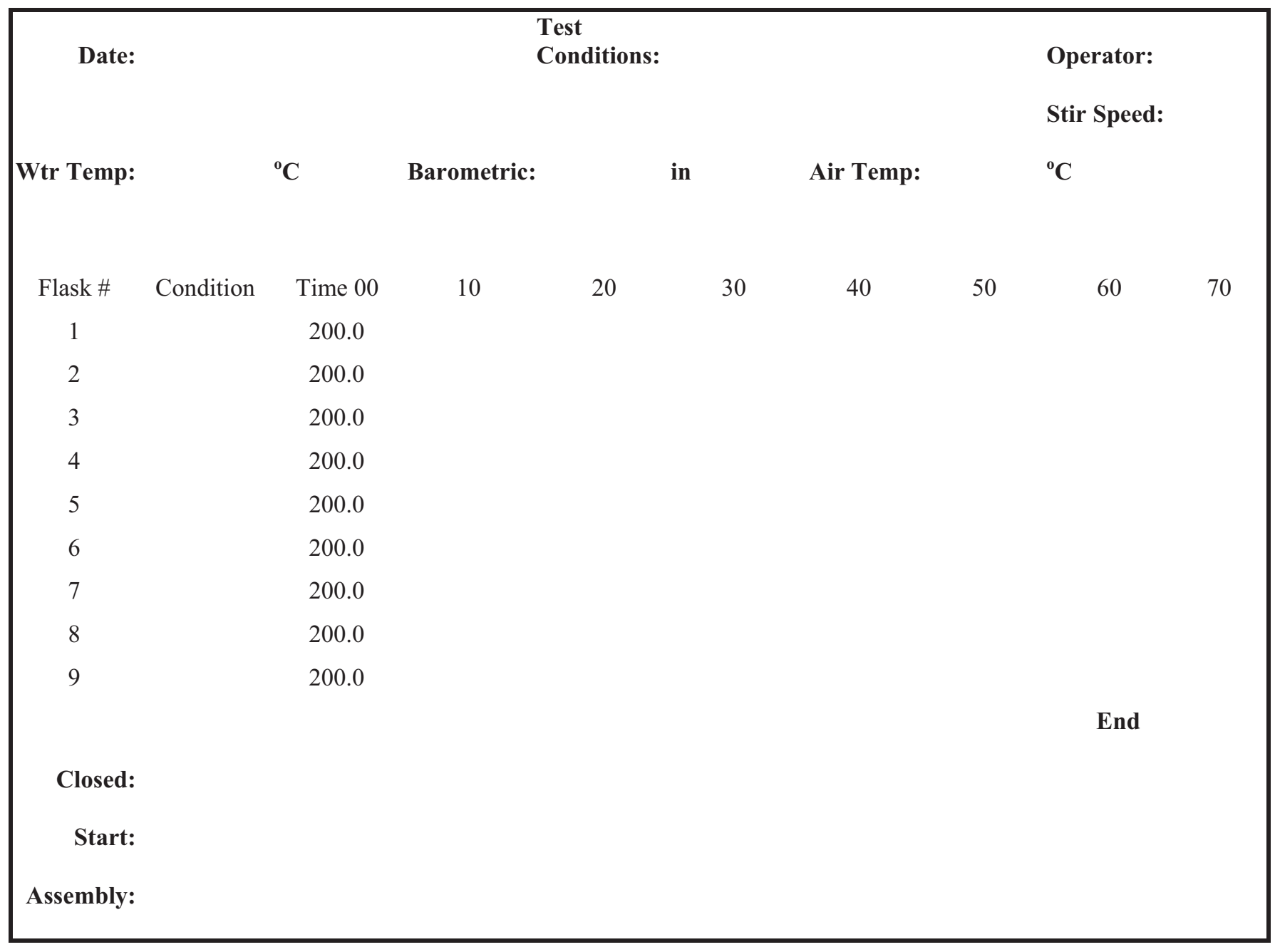


Stir Speed - shaker speed for rocker arm holding respirometry flasks

Assembly - the time when the first respirometer flask is placed in the water bath

Start - the time the last respirometer flask is placed in the water bath

Closed - the time when the respirometer flasks are closed (5-minutes after strart time for $15 \mathrm{~mL}$ respirometer flasks)

The readings were converted to standard temperature and pressure values using:

$$
u l(\mathrm{STP})=\frac{(u 1 \text {-reading }) \mathrm{X}(\text { Room barometric pressure }) \mathrm{X}\left(273^{\circ} \mathrm{K}\right)}{760 \text { torr X Waterbath Temp in }{ }^{\circ} \mathrm{K}}
$$

This value was converted to microliters of oxygen (STP) and then to micrograms of oxygen consumed. These are typical values that are useful when comparing overall test results to other work. At $\mathrm{STP}$, the density of oxygen in air is 1.43 grams per liter, or 1.43 micrograms per microliter.

$$
\frac{u 1(\mathrm{STP}) \mathrm{X}\left(32-u \mathrm{~g} \mathrm{O}_{2}\right)}{22.4 \mathrm{ul}}=u \mathrm{~g} \mathrm{O}_{2}
$$

At the end of a test the results for the same test parameters were added together, averaged and then plotted. A trend line, based on cumulative microliters of air consumed over time, was calculated for the first thirty minutes of the test for each parameter. A second trend line was calculated for the whole test ( 70-minutes). These trend lines represent respiration rates for the parameters tested. Cell counts were performed on samples collected from the tests, and results were normalized for cell numbers.

\section{TEST RESULTS AND DISCUSSION}

A series of respirometric experiments were conducted using geothermal sample water collected from Sonoma cooling tower basin. The experiments investigated the impact of adding phosphate and nitrate additions to existing microbial populations in the sample water and to populations of sulfatereducing (Desulfovibrio vulgaris) and sulfur-oxidizing (Thiobacillus neopolitanus) bacteria introduced into water from laboratory cultures. The various test scenarios are summarized in Table 3. 
Table 3. Test Conditions for Respirometry Experiments

\begin{tabular}{|c|c|c|c|c|}
\hline Series & Date & Control & 1 & 2 \\
\hline $1 \mathrm{a}$ & Nov-13-03 & control & SRBs & SRBs $+20 p p m$ sulfate \\
\hline $1 \mathrm{a}$ & Dec-23-03 & control & SRBs & $\mathrm{SRBs}+\mathrm{P} / \mathrm{N}$ \\
\hline $1 \mathrm{a}$ & Jan-05-04 & control & SRBs & $\mathrm{SRBs}+\mathrm{P} / \mathrm{N}$ \\
\hline $1 \mathrm{~b}$ & Jan-14-04 & SRBs & $20 \mathrm{~N}$ & $40 \mathrm{~N}$ \\
\hline $1 \mathrm{~b}$ & Feb-10-04 & SRBs & $20 \mathrm{~N}$ & $40 \mathrm{~N}$ \\
\hline $2 \mathrm{a}$ & Feb-16-04 & control & $20 \mathrm{~N}$ & $40 \mathrm{~N}$ \\
\hline $2 \mathrm{a}$ & Feb-17-04 & control & $20 \mathrm{~N}$ & $40 \mathrm{~N}$ \\
\hline $2 \mathrm{a}$ & Feb-18-04 & control & $20 \mathrm{~N}$ & $40 \mathrm{~N}$ \\
\hline $2 \mathrm{a}$ & Feb-19-04 & control & $20 \mathrm{~N}$ & $40 \mathrm{~N}$ \\
\hline $3 a$ & Feb-26-04 & control & $20 p$ & $40 p$ \\
\hline $3 \mathrm{a}$ & Mar-02-04 & control & $20 p$ & $40 p$ \\
\hline $3 \mathrm{a}$ & Mar-06-04 & control & $20 p$ & $40 p$ \\
\hline $3 \mathrm{a}$ & Mar-09-04 & control & $20 p$ & $40 p$ \\
\hline $2 b$ & Apr-08-04 & control & $20 n$ & 40n (new water) \\
\hline $2 \mathrm{~b}$ & Apr-13-04 & control & $20 n$ & 40n (new water) \\
\hline $3 \mathrm{~b}$ & May-09-04 & $20 n$ & $20 p$ & $20 \mathrm{np}$ \\
\hline $3 \mathrm{~b}$ & May-11-04 & $20 n$ & $20 p$ & 20np \\
\hline $3 \mathrm{~b}$ & May-12-04 & $20 n$ & $20 p$ & 20np \\
\hline 4 & Jun-11-04 & $20 p$ & 1Sulfide & 2Sulfide \\
\hline 4 & Jun-24-04 & $20 p$ & 1Sulfide & 2Sulfide \\
\hline 4 & Jun-28-04 & $20 p$ & 1Sulfide & 2Sulfide \\
\hline 5 & Jul-02-04 & 1Sulfide & $20 p$ & $40 p$ \\
\hline 5 & Jul-09-04 & 1Sulfide & $20 p$ & $40 p$ \\
\hline 6 & Aug-11-04 & 1Sulfide & $20 n$ & $40 n$ \\
\hline 6 & Aug-12-04 & 1Sulfide & $20 n$ & $40 n$ \\
\hline 6 & Aug-13-04 & 1Sulfide & $20 n$ & $40 n$ \\
\hline 7 & Sep-08-04 & $1 \mathrm{Sul}+1 \mathrm{~S} / \mathrm{O}$ & $1 \mathrm{Sul}+1 \mathrm{~S} / \mathrm{O}+2 \mathrm{P}$ & $1 \mathrm{Sul}+1 \mathrm{~S} / \mathrm{O}+4 \mathrm{P}$ \\
\hline 7 & Sep-09-04 & $1 \mathrm{Sul}+2 \mathrm{P}$ & $1 \mathrm{Sul}+1 \mathrm{~S} / \mathrm{O}+2 \mathrm{P}$ & $1 \mathrm{Sul}+2 \mathrm{~S} / \mathrm{O}+2 \mathrm{P}$ \\
\hline 7 & Sep-10-04 & $1 \mathrm{Sul}+2 \mathrm{P}$ & $1 \mathrm{Sul}+1 \mathrm{~S} / \mathrm{O}+2 \mathrm{P}$ & $1 \mathrm{Sul}+2 \mathrm{~S} / \mathrm{O}+2 \mathrm{P}$ \\
\hline 7 & Sep-11-04 & $1 \mathrm{Sul}+2 \mathrm{P}$ & $1 \mathrm{Sul}+1 \mathrm{~S} / \mathrm{O}+2 \mathrm{P}$ & $1 \mathrm{Sul}+2 \mathrm{~S} / \mathrm{O}+2 \mathrm{P}$ \\
\hline 7 & Sep-15-04 & 1Sulfide & $1 \mathrm{Sul}+1 \mathrm{~S} / \mathrm{O}$ & $1 \mathrm{Sul}+1 \mathrm{~S} / \mathrm{O}+2 \mathrm{P}$ \\
\hline 7 & Sep-16-04 & 1Sulfide & $1 \mathrm{Sul}+1 \mathrm{~S} / \mathrm{O}$ & $1 \mathrm{Sul}+1 \mathrm{~S} / \mathrm{O}+2 \mathrm{P}$ \\
\hline
\end{tabular}

\section{Table Notes:}

SRBs - sulfate reducing bacteria

$\mathrm{N} / \mathrm{n}$ - nitrate, a prepared, sterile solution of sodium nitrate

20n, 40n-20ppm or 40ppm nitrate solution

$\mathrm{P} / \mathrm{p}$ - phosphate, a prepared, sterile solution of sodium phosphate, monobasic

20p, 40p - 20ppm phosphate, 40ppm phosphate solution

20np - 20ppm nitrate and 20ppm phosphate solution

Sulfide (Sul) - a sterile, 1/10 dilution of a saturated sodium sulfide solution

$\mathrm{S} / \mathrm{O}$ - Sulphur-oxidizing bacteria

New water - water collected from the Sonoma Cooling Tower Basin on 03/31/04 (previous water was collected $(10 / 08 / 03)$ 
Test Series 1a \& $1 \mathbf{b}$ were the first sets of experiments conducted with the Sonoma geothermal cooling tower basin water (GCTBW). Data from this series guided the choice of parameters for the tests that followed. The tests were set up to compare the background respiration of the indigenous bacteria (control sample) in the GCTBW to the addition of sulfate reducing bacteria and the addition of nutrients. Results, presented in Figure 3, indicated there was an increase in the respiration rate with the addition of the SRBs and nutrients. However there was not a significant difference between the addition of the SRBs only and the addition of the nutrients. A decision was made at this point to discontinue the addition of cultured SRBs to the tests. This was based on the following:

1. There was evidence of measurable levels of respiration with the indigenous microbial population.

2. There was some concern of maintaining a stable culture of sulfate reducing bacteria over the entire planned test period. The prime consideration was whether changing culture status would influence respirometry measurements and complicate cross-comparison of results.

3. The addition of nutrients exhibited a change in the respiration rate in comparison to the control flasks. The primary interest was with assessing the potential impact of adding the Sonoma TTW to the cooling tower basin.

From these tests it was apparent that respiration with these volumes approached an asymptotic limit after 70 minutes. There was evidence of a steeper respiration slope in the first thirty minutes of testing, followed by a gradual reduction of activity out to 60 minutes.

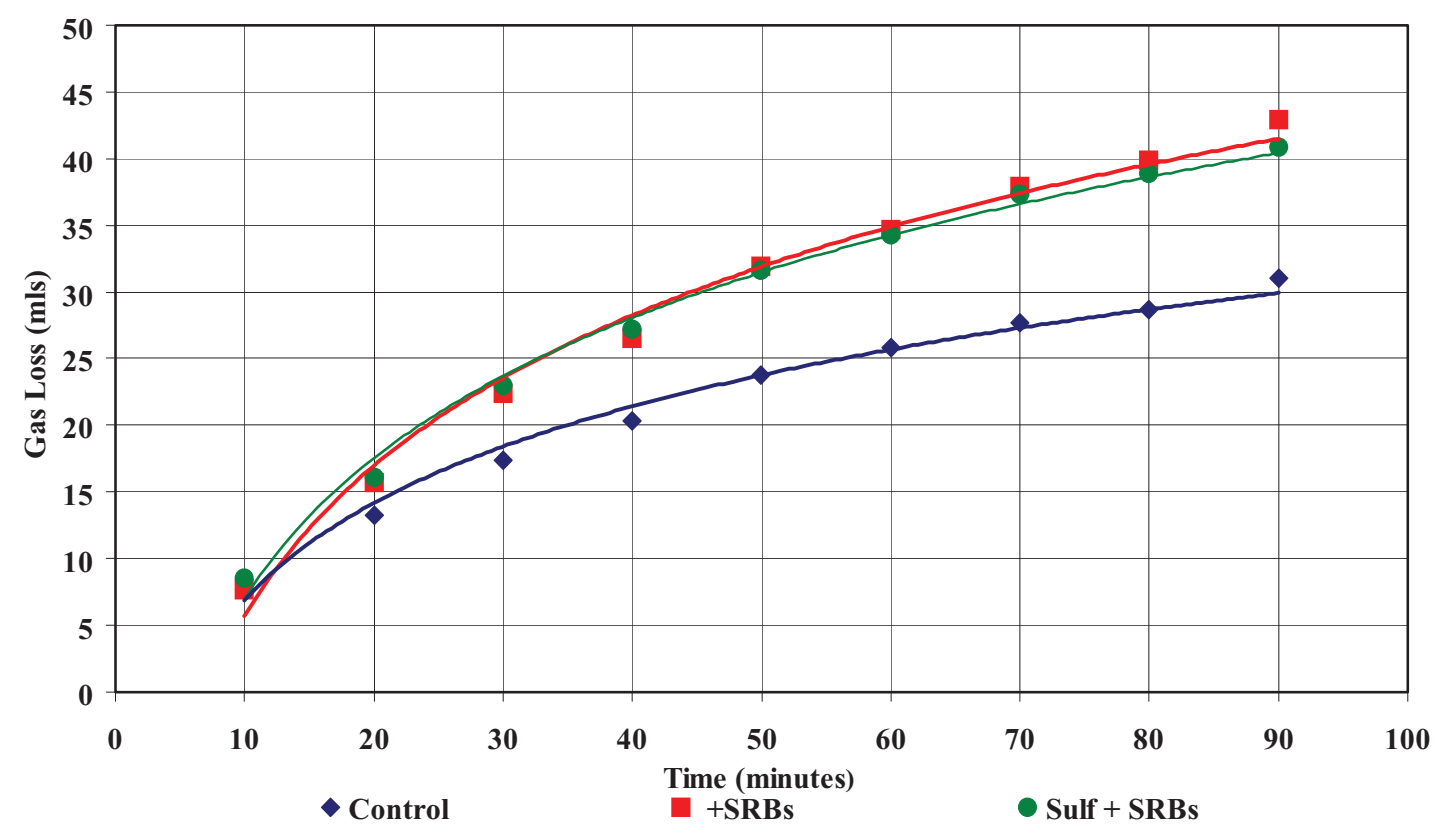

Figure 3. Test 1a - Respiration Rate Change with the Addition of SRBs and SRBs Plus Sulfate 


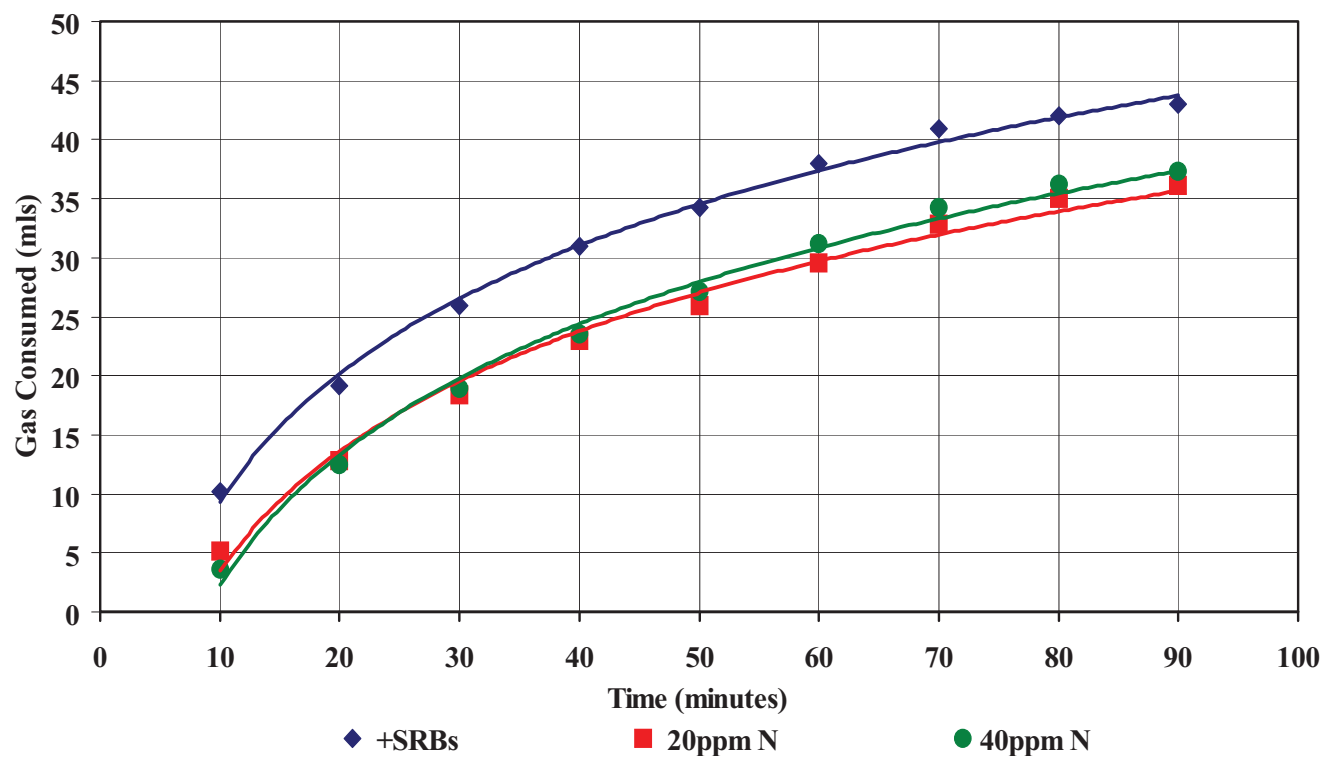

Figure 4. Test $1 \mathrm{~b}$ - Respiration Rate Change with the Separate Additions of SRBs and Nitrate

Test Series 2a \& 3a were replicate tests were conducted to determine repeatability. Both nitrate and phosphate additions were examined as single nutrient additions. During each test a $20 \mathrm{ppm}$ and a $40 \mathrm{ppm}$ concentration was compared to a baseline, or control, condition. The addition of nitrates had a greater effect on the respiration rate in comparison to the phosphate tests. There was an indication that respiration rate increased as more nitrate was added. This was not as evident with the phosphate tests, which sometimes resulted in higher levels of activity in the lower $(20 \mathrm{ppm})$ nutrient concentration. The higher concentration of phosphates may be chemically complexing with minerals and other materials in the geothermal water. It is also noted that the respiration rate does not scale linearly with concentration. The fact that only slight increases are detected may be attributed to growth kinetics of the organisms, i.e. they may not be able to use any more of the nutrient in their current growth phase over this time frame. 


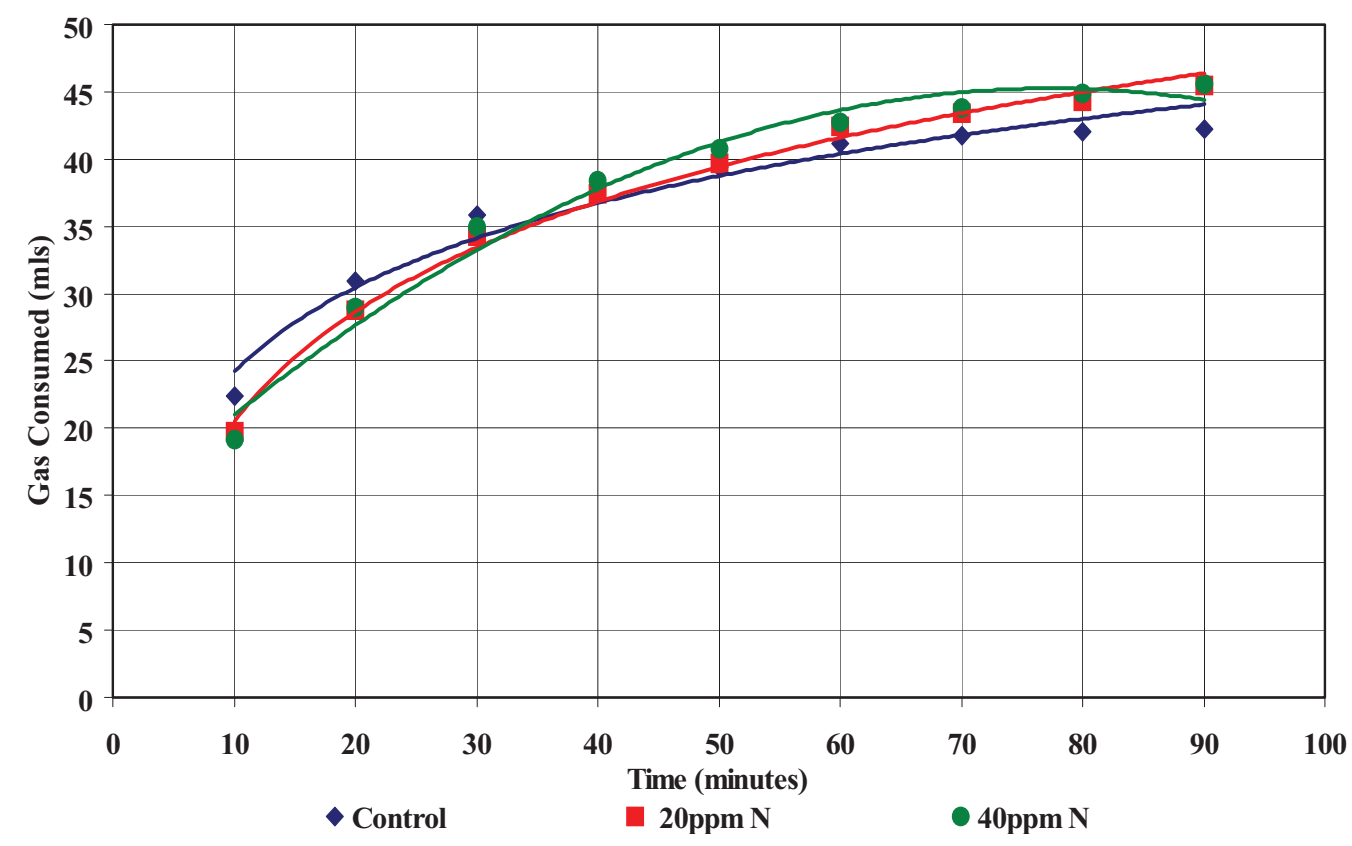

Figure 5. Test 2a - Respiration Rate Change with Varying Nitrate Concentrations

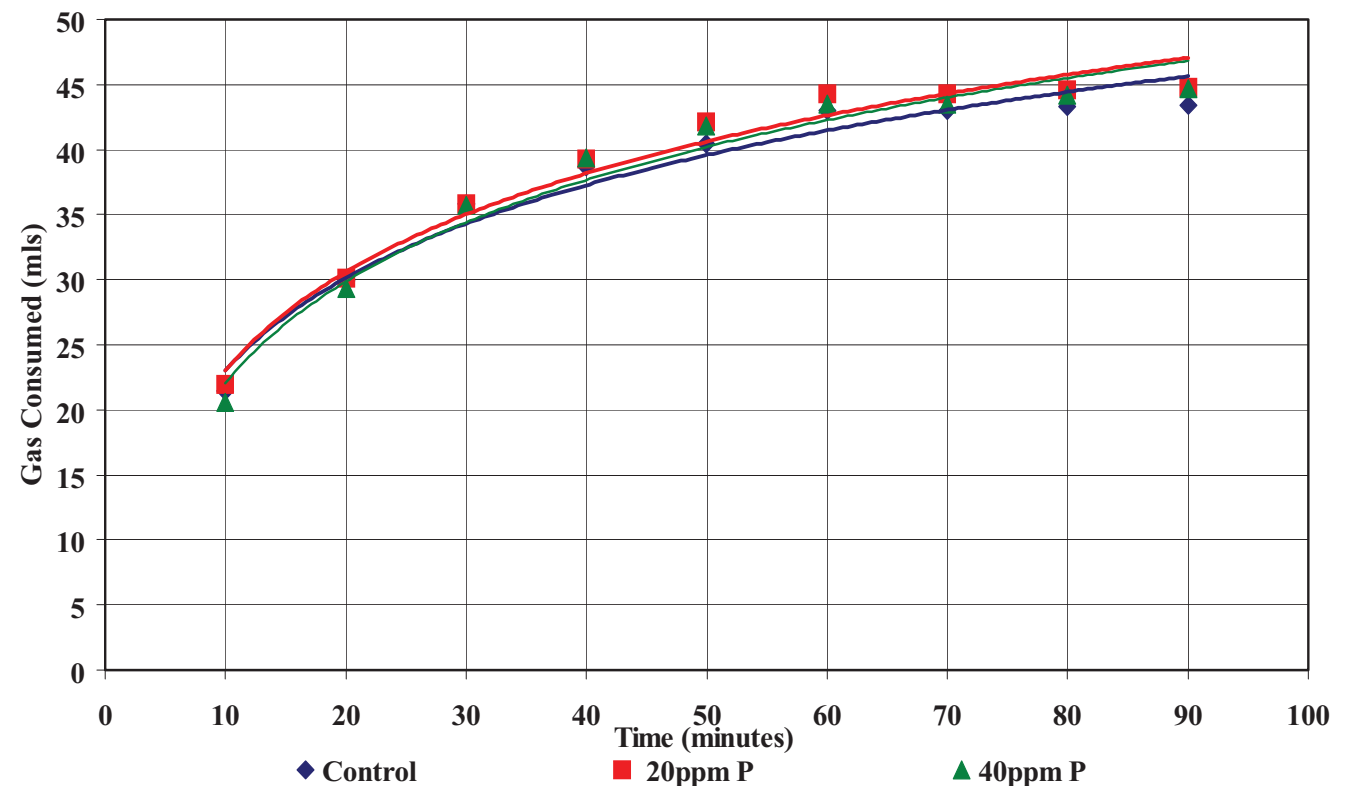

Figure 6. Test 3a-Respiration Rate Change with Varying Phosphate Concentrations

Test Series $\mathbf{2 b} \boldsymbol{\mathbf { b }} \mathbf{3} \mathbf{b}$ were the same series of tests conducted previously but using the new Sonoma CTBW, collected on March 31, 2004. The sulfate concentration in this water $(225 \mathrm{ppm})$ was less than the previous Sonoma CTBW (1200ppm) tested. After consulting with Calpine Geothermal personnel, it was concluded that the lower sulfate concentration may be due to recent rains in the area at the time of collection diluting the dissolved materials in the cooling tower basin. A similar pattern was 
detected in this sample with the addition of nitrates producing a higher respiration rate in comparison to the addition of phosphates.

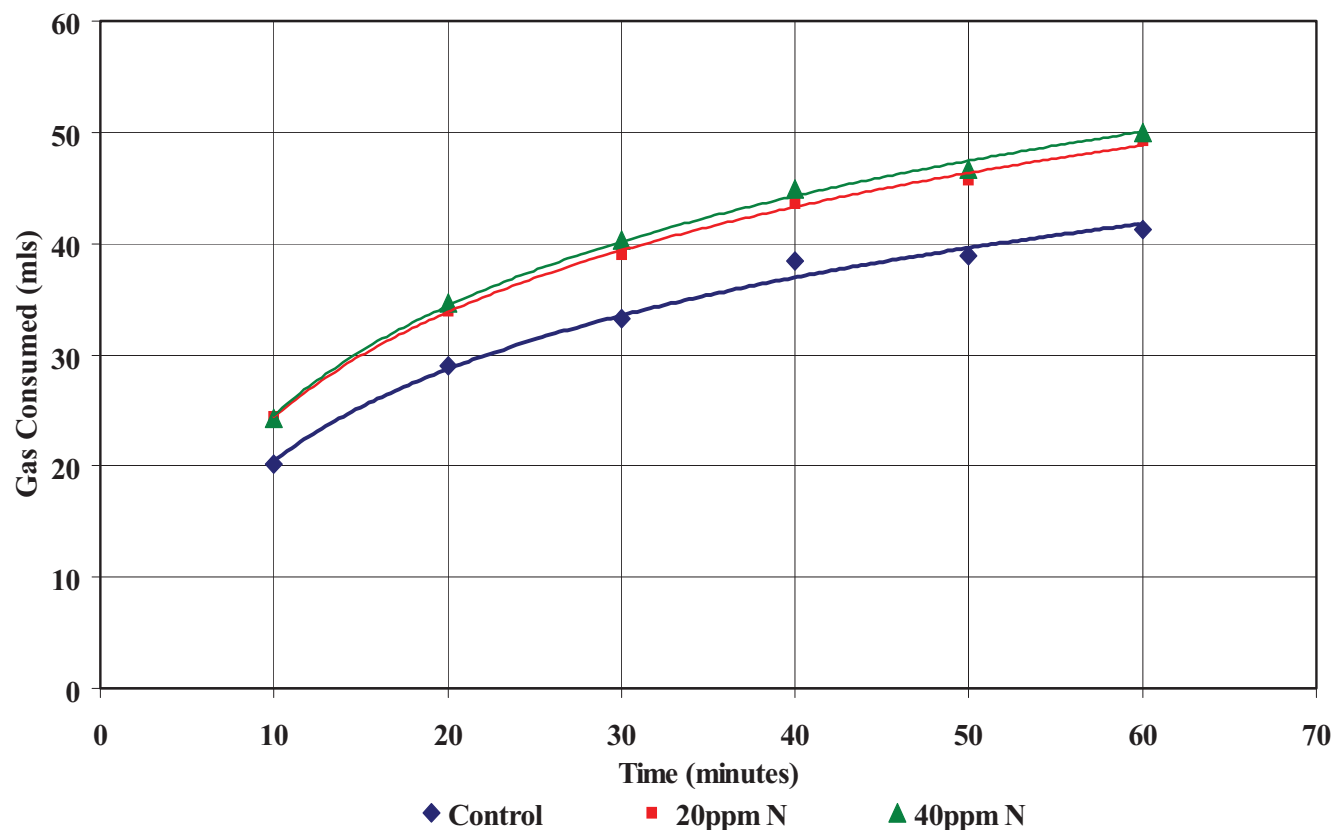

Figure 7. Test $2 b-$ Respiration Rate Change with Varying Nitrate Collected from New Sonoma Water Sample

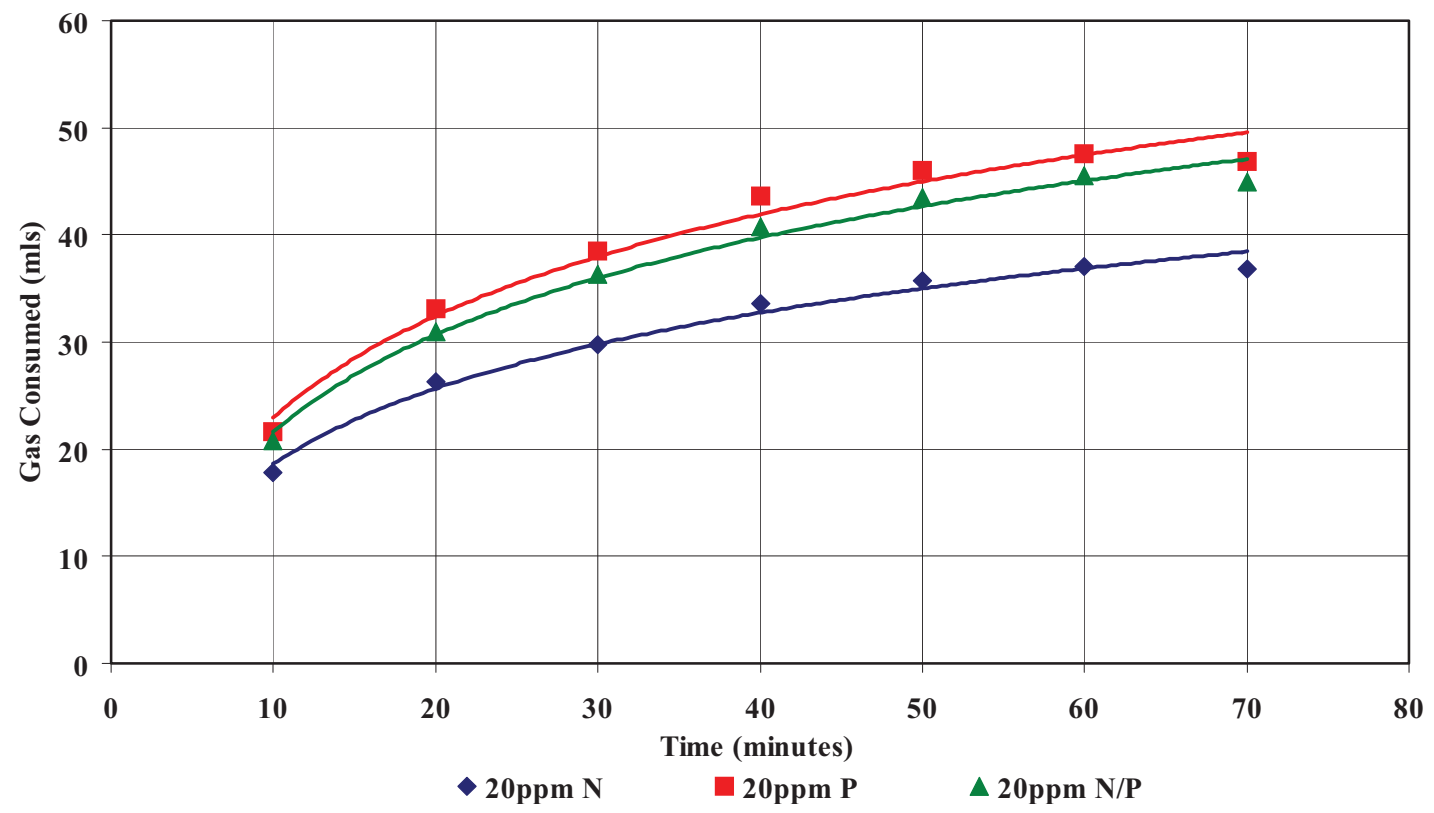

Figure 8. Test $3 b$ - Respiration Rate Change with Varying Nitrate and Phosphate Concentration Using New Sonoma Water Sample 
Test Series 4 was set up to test the addition of sulfides into the Sonoma water. While there were dramatic differences observed in the results of this test there are uncertainties associated with the interpretation of the data. Sulfides can be trapped in an alkaline solution, similar to carbon dioxide. The center well of the respirometer flask also contains a $0.1 \mathrm{~N}$ sodium hydroxide solution. The purpose is to catch fugitive $\mathrm{CO}_{2}$ from the head-space (see previous discussion on respirometry). There were however, other indications the addition of sulfide was affecting the natural population of microbes. The sulfate analyses indicated a slightly higher concentration of sulfate at the end of the experiment in the flasks that received sulfide additions, which is consistent with an increase sulfur oxidation due to microbial action.

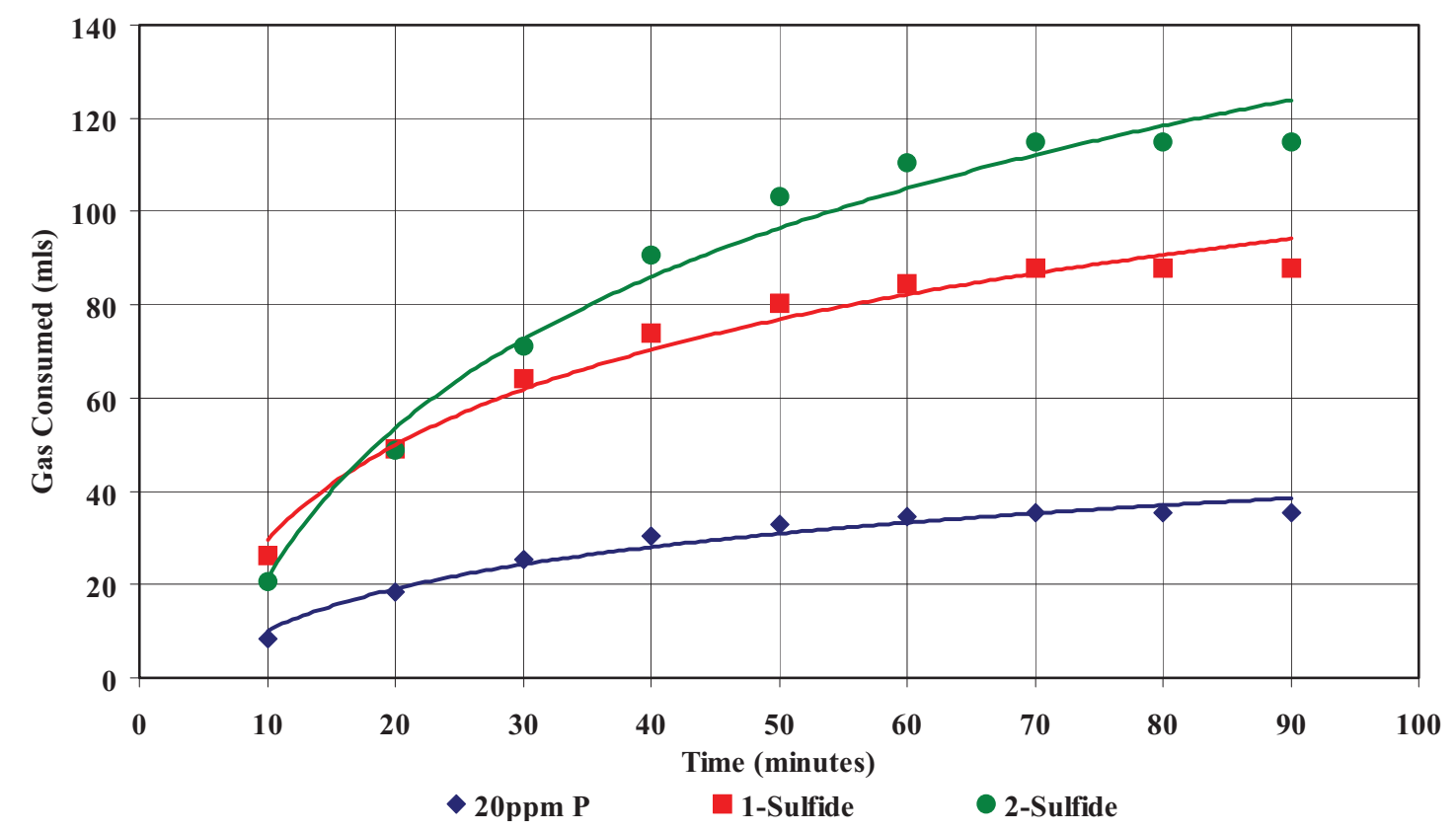

Figure 9. Test 4 - Respiration Rate Change with Sulfide Additions

Test Series 5 and 6 were designed to test the addition of a constant concentration of sulfide with increased nutrient additions. Series 5 tested 20ppm and 40ppm concen-trations of phosphate, and Series 6 tested nitrate additions. The results were very similar for both chemicals. There was a slight increase in the $20 \mathrm{ppm}$ concentration addition, with a slight decrease in the respiration rate for the $40 \mathrm{ppm}$ concentration. 


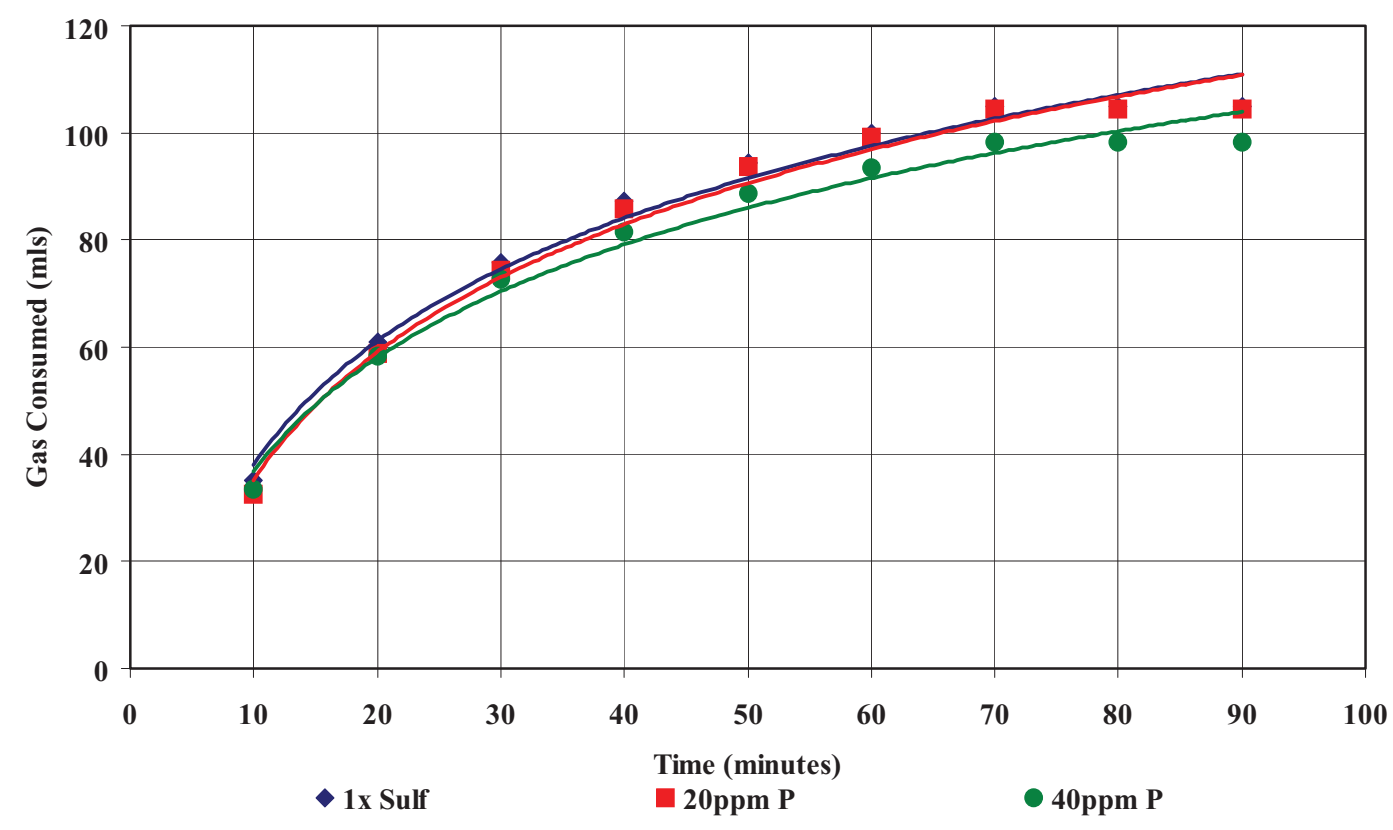

Figure 10. Test 5 - Respiration Rate Change with Sulfide and Phosphate Additions

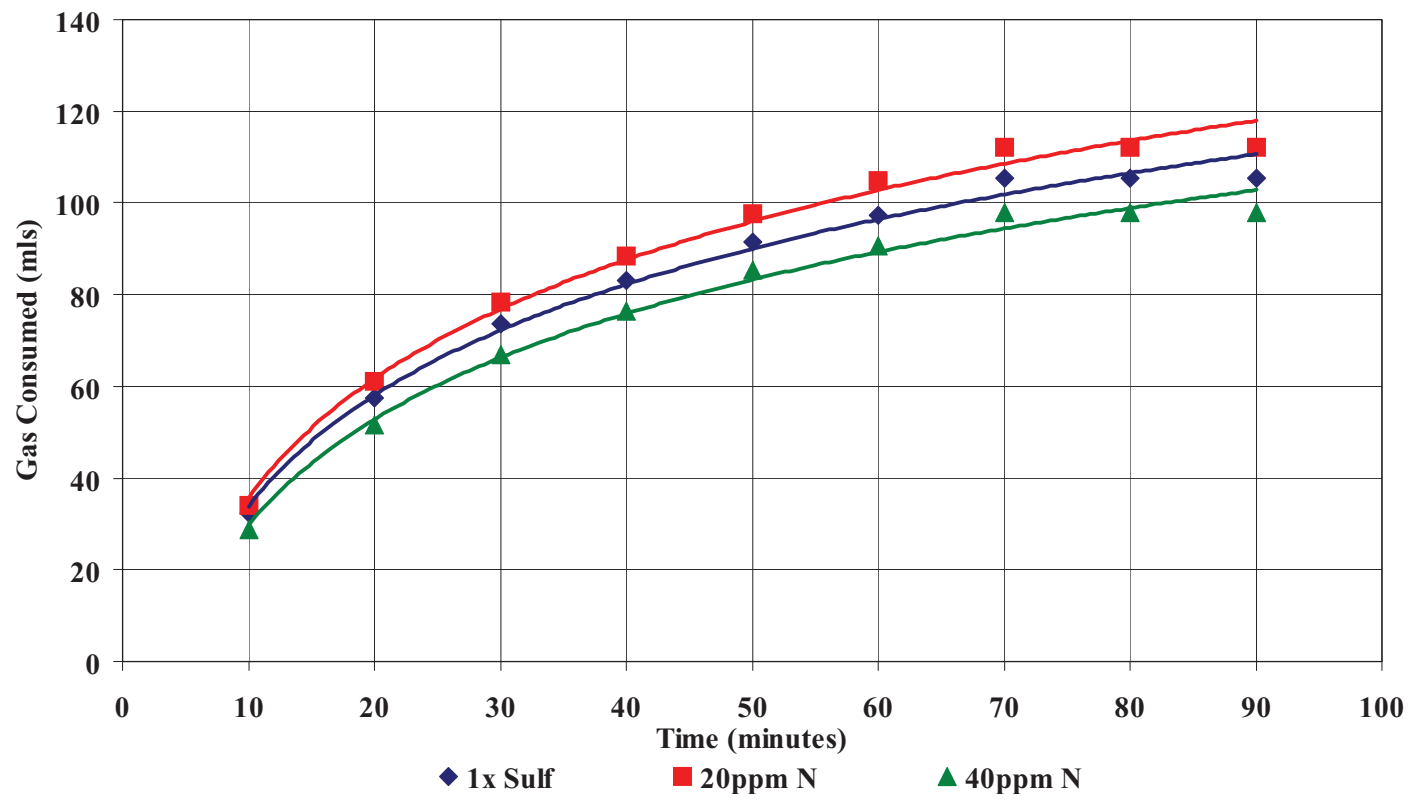

Figure 11. Test 6 - Respiration Rate Change with Sulfide and Nitrate Additions 
Test Series 7 was conducted to see if the addition of sulfate-oxidizing bacteria into the Sonoma water with the nutrient phosphate would enhance sulfide reduction.

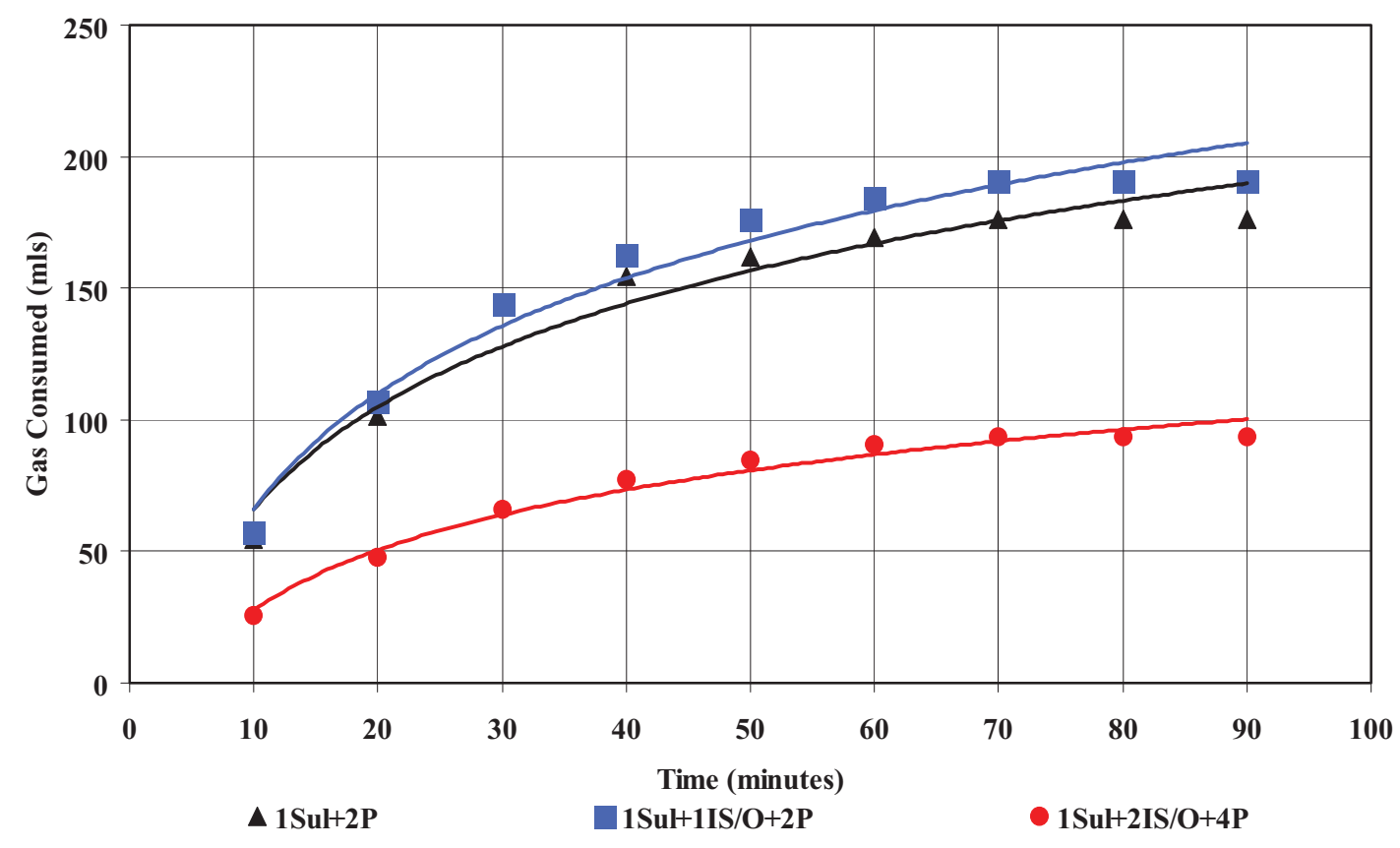

Figure 12. Test 7 - Respiration Rate Change with Sulfur-Oxidizing Bacteria and Phosphate Additions

A sodium sulfide solution is added to the basin water along with an inoculum of sulfur-oxidizing bacteria. The addition of these bacteria resulted in an increased respiration rate, while the doubling of the phosphate concentration significantly decreased the rate. The latter effect supports the premise that phosphate may bind with other chemical compounds in the solution, and therefore is not immediately available in a form the bacteria can use.

\section{CONCLUSIONS}

The results of these scoping experiments indicate that respirometry can be a useful method for observing the impact of nutrient additions associated with the Sonoma tertiary treated water in the cooling tower basin water. Both nitrate and phosphate additions produced detectable changes in the rate of microbial activity in the indigenous population of bacteria. Results from experiments taken with water samples collected at differing times also showed similar trends. The range of nutrient concentrations added in these experiments may have been too broad since at times the higher concentrations produced lower rates of respiration. Possible explanations for the lower rates include chemical complexation at the higher concentrations and/or exceeding the acceptable nutrient concentration that the bacteria could readily use.

Since the experiments were conducted on water samples collected from the basin, shipped to the laboratory, stored at $4^{\circ} \mathrm{C}$ and then tested, it is very likely that under these conditions the natural 
population of bacteria were stressed. Consequently, they may not be as active as the microbes would be if sampled and processed immediately. Based upon these tests results, the respirometric technique for tracking microbial activity in the geothermal basin is feasible and would be even more effective if it could be used on site and implemented as an on-line technique. 